\title{
The Power of Extrinsic Motivation in Tertiary Education
}

\author{
Emilie Joy Kistnasamy* \\ Community Health Studies, Faculty of Health Sciences, Durban University of Technology, Durban, Kwazulu-Natal, South Africa \\ *Corresponding author: JoyK@dut.ac.za
}

Received May 16, 2014; Revised June 04, 2014; Accepted June 05, 2014

\begin{abstract}
Motivation is one of the most significant psychological concepts in education and can be indicated by the achievement of personal goal setting and developing an interest in the subject area; and reliance on external rewards and pressures. Successful students have a continuous motivating cycle of reflection, connection, confidence and positive self-esteem. Therefore, it is imperative for an educator in a tertiary setting to create a positive and encouraging environment that enhances student learning and personal fulfilment. This article looks at the power of extrinsic motivation as implemented in various modes at a University in Durban, South Africa. Four main categories of extrinsic motivation are discussed. Each category is underpinned by examples used to motivate the student to achieve excellence and thrive successfully. The benefits of implementing the various motivation techniques have shown decreased or minimal absenteeism, students endeavouring to achieve $75 \%$ and above for each assessment, a sense of accomplishment for the student, an increase in general well-being and personal empowerment and an enhancing of best teaching and learning practices.
\end{abstract}

Keywords: extrinsic motivation, tertiary education, students, educator, South Africa

Cite This Article: Emilie Joy Kistnasamy, “The Power of Extrinsic Motivation in Tertiary Education." American Journal of Educational Research, vol. 2, no. 6 (2014): 383-388. doi: 10.12691/education-2-6-9.

\section{Introduction}

Intrinsic or extrinsic motivation is acknowledged as one of the most significant psychological concepts in education [1] and can respectively, be indicated by the achievement of personal goal setting and developing an interest in the subject area; and reliance on external rewards and pressures. When students are successful, it results in a continuous motivating cycle of reflection, connection, confidence and positive self-esteem. [2,3] Therefore, it is imperative for an educator in a tertiary setting to create a positive environment that enhances encouragement and propagates a safe environment for learning and personal fulfilment. When there is a sense of victory, students will "sacrifice to succeed, look for ways to win, become energized, follow the game plan and help other team members" [4] which all greatly contributes to developing attributes that can only enhance the graduate's future professional status [5].

A study conducted at two Swedish universities concluded that even though motivation should be intrinsic, dedicated educators using a choice of teaching, learning and assessment methods, enhanced enthusiasm and learning. [6] This conclusion was further supported by [7] whose position was that "academic staff can enhance the effectiveness of learning interventions by using methodologies that go beyond traditional subject-related knowledge transfer." Extrinsic motivation in tertiary education works best when educators promote best practices like incorporating a variety of teaching methods and further, displaying verbal and non-verbal behaviours that create a positive impression and stimulate learners' interest. [8] These behaviours can include a) communications of expectations and values, b) providing help, advice and instruction, c) creating a safe environment, d) providing emotional support [9] and e) developing students' proactive participation in the learning process. [10] Further, relating content to students' need, concerns, goals, interests and experiences; encouraging students to use self-talk and affirmation and emphasizing that increased effort will most likely lead to success and add great value to student motivation [11].

The following content therefore explores implementing various extrinsic motivation techniques in a South African tertiary educational setting to encourage students to become the best that they can be, given the potential that is within them.

\section{The South African Context}

South Africa, even though a developing country, has a rich history of using education as a platform to better itself. This was never more evident during the apartheid years when non-white students were disadvantaged in many ways, inclusive of educational segregation, but still had a strong will to persevere and succeed. In numerous instances, and even though literature has repeatedly reported that there are positive associations between children's social background and their academic achievement [12], career fulfilment was achieved in spite of the difficult social and political circumstances. In 1994, with the advent of a free and democratic country, this previous limitation on educational access was eradicated 
and educational access became all inclusive. However, even though we are twenty years into democracy, there still currently exists, many social, cultural, traditional and societal norms and barriers that can and do impact negatively on how students perceive themselves in this progressive educational setting. Added to this, is the immense peer pressure, the financial constraints and the added stress of proving oneself in a new and unfamiliar setting which differs vastly from a high school setting. Many are thrust into an ill-prepared young adulthood where responsibility and accountability is taken as given. In this fast paced setting, a students' emotional growth can either be totally destroyed or nurtured to reach personal fulfillment.

In my almost fifteen years as an educator at a tertiary institution, many hours have been spent (during and after normal working hours) listening to tragic experiences and then trying, together with the student, to find practical and feasible solutions to those problems that are impacting negatively on their studies. Some of the experiences are so horrendous, the tears shed so pitiful and heart-breaking, that there is a wonder as to where is mankind going to? No matter how objective I am, a little part of me is always saddened and disillusioned by the emotional cruelty that is experienced by these young people. The more educated, the more wealthy, the more empowered, the more literate, the more democratic, the more everything we as society have become, the more we seem to be unable to express our thoughts, our feelings, our hurts, our disappointments, our anguish, our pain and when we do express these emotions verbally, they often come out as cutting, bitter, unforgiving, destructive and devastating words. To this end, the following extrinsic motivation techniques were developed and implemented after researching and adapting ideas and collating thoughts on how best to help students help themselves.

\subsection{The Power of Words}

Positive reinforcement and constructive criticism never hurts, shatters or demeans. Negative reinforcement, on the other hand, can destroy dreams, hopes, goals and selfconfidence. As educators, we should endeavour to never to play a role in the latter. How differently students can turn out when words like the following are uttered: "What is the matter with you? You are so useless! With an attitude like this, no wonder you failed" The list is endless. What power, as educators, we hold in our words! The two case studies below further elaborate on this concept.

\subsubsection{Case Study 1}

A student in both of my final year undergraduate classes failed his tests in the 1st term and attained marks less than 20\%. I was quite dismayed at this. So firstly, I wondered where did I go wrong? What gaps existed in my teaching methodology that may have contributed to his failure? As well as reflecting on my teaching methods, I requested that he pay me a visit. When he entered the office, he was extremely nervous and fearful - obviously expecting the worse. The only words I said to him were: "Name, I believe that YOU have the POTENTIAL to do exceedingly well. (Pause) Bye-bye." Well, there was silence for a minute and then he said: "Excuse me, Joy?" I said: "Name, I believe that YOU have the POTENTIAL to do exceedingly well. (Pause) Bye-bye." "Is that it?" he said. I said: "Yes, that's it!"

With evident bewilderment, he left. I later found out that his dad had passed away just prior to his writing these tests and this had obviously impacted on him emotionally as his test marks bore testimony to that fact. The 2nd term saw him attain $90 \%$ s' in both tests as well as a remarkable improvement in all other final year undergraduate subjects. At year end, he won the departmental prize for the most improved student, obtained employment with the South African Defence Force and went on to complete his Honours degree. He subsequently informed me that those words that I uttered to him in his 3rd year made a profound impact on him and gave him the courage to persevere.

\subsubsection{Case Study 2}

A final year female undergraduate student sent me an email at year end which gave me much food for thought and left me, humbled. The following is just an extract:

“...I am generally a very shy person and in order to improve in my school work, I have to participate in class a lot but since I arrived at this Institution, I have had the problem of not doing my best because I would not talk in class as I would think of various reasons before I even lift my hands, for example: my background. Most of the students came from very good backgrounds and from multiracial schools and they are very fluent in English. So, I generally ask myself: who are you to open your mouth? This lowered my selfesteem even more because I know if I am free to talk or participate in class, I also will do well in my work. But since I came into your class, everything changed because if I whispered an answer in class, you will shout it to the whole class and make me elaborate more on that. That made me feel so special and whatever I say, you will say: "You are sharp”..that alone made me feel so special. This whole thing did not only affect my results in your subjects but with other subjects as well. I now had the courage to stand up and talk in front of the whole class despite what I am wearing or what the other person looking at me is going to say but I just do it with self-confidence because of your inspiration...You have made me to be myself again. THANK YOU!! May God help you to carry on being the person you are."

Both the above case studies show that words can help an individual cope effectively with the past so that s/he can get on with the present and will not lose the future. Words can assist in the emotional, cultural and social healing process - lift and 'bandage' broken wings so that an individual can soar like an eagle, even in the midst of adversity. Words convey to the listener that in addition to having intelligence, that as an educator, you can also have an empathetic mind and a compassionate heart - hearing that which is not necessarily spoken yet feeling the hurt and agony in the individual and resolving to help in a solution oriented manner.

\subsection{The Power of Belief}

The achievement of personal goals is underpinned by students realising that any current activity given in class is a step towards that final goal [13] and when this form of thinking becomes a mind-set, the value and promising 
opportunities of every activity from then on, is appreciated. Therefore as the educator in charge, there is a need to demonstrate a passion for the upliftment of each student and, to do so with enthusiasm. [14] This can be difficult to demonstrate, but if done with integrity, it will be apparent to the audience. Kittrell and Moore in their article on student motivation [15] suggested some motivational strategies that can be used in order to get students to believe in themselves: a) get to know your students, b) relate the course material to real life situations and uses, c) explain your expectations, d) be enthusiastic, e) provide a satisfactory environment and f) provide positive reinforcement. "If students have low expectations for success on a task, they may be more likely to give up easily, attribute their failure to a lack of ability, and attribute their success to external factors such as luck or ease of the task.” [16]

In order to assist students understand and harness the power of self-belief, I adapted, created and have implemented the following motivational techniques:

\subsubsection{The A+Certificate (See Appendix A)}

This certificate is given to each student on the first day of lectures. The $\mathrm{A}+$ is used as a constant reminder that they can achieve $75 \%$ and above and do so with excellence. Many students have reported that they paste this certificate on their dorm walls so that it motivates them to do well. When they see the $\mathrm{A}+$, they believe they can attain it as the educator believes that they are worthy of it. I was criticised for this as I was told that the A+ places too much pressure on the student to succeed. My intention is not to place pressure but to get students to believe that they can achieve their best. This helps in developing a spirit of excellence and not perfection as perfection leaves no room for definitive growth and progressive change.

\subsubsection{Learner's Details Card}

Every student is given this to complete on the first day of lectures. It has a place for the student's picture, student's details inclusive of what name would s/he would prefer to be addressed by, date of birth and all contact details. Additionally, the parent's or primary caregiver's details are requested inclusive of name, contact details and postal addresses.

This card has multi-fold purposes.

- Purpose 1: I get to learn the students' name. I was informed very early in my career by the students that an educator knowing their names matters much!

- Purpose 2: If a student is absent from class, I am aware of this and immediately after class, I will telephone the student to let him/her know that s/he was missed in class and that I hope all is well.

- Purpose 3: The birth dates are important as I have made a birthday card which is e-mailed to each student on their birthday. Also, once-a-quarter, I celebrate with those students by having a birthday party where the whole class is invited to attend and which is sponsored by me. To see the happiness and pleasure on the birthday persons' faces is immeasurable. Some have even informed me that this is the $1^{\text {st }}$ birthday party they have ever had!

- Purpose 4: My students are informed at the beginning of the year that I will be posting after mid- year, a letter to each parent/caregiver acknowledging their amazing parenting skills (sometimes in the midst of real difficult financial, emotional and social circumstances) and giving praise to their child who is my student and who has made invaluable and excellent contributions to his/her own education while being respectful of peers and the educator. This seems to act as a catalyst for the students to improve on all aspects of their education. The responses from parents/caregivers have been phenomenal. Most were petrified to even open the envelope thinking that it was just another financial statement from the university. However, on reading the letter, parents celebrated in awe. Students also informed that the relationships with their families were much improved

\subsubsection{One-on-one Meetings}

These are 15-30 minute meetings which I schedule in the $2^{\text {nd }}$ term of the university calendar. I do not schedule these meetings in the $1^{\text {st }}$ term as my students do not yet know me. I want to firstly create and build on an atmosphere of mutual trust, respect, safety and security. When these meetings are held, then this safe space is now clearly defined and fully protected. I have always being of the opinion that I must, as an educator, be constantly learning and one of the best ways to learn is from the client.

This 'safe' conversation is based on the following 4 questions:

a) How am I, as the educator, adding value to your learning process at our university?

b) How can I improve so that you get the best possible learning experience in our class?

c) How are you coping with this subject and with university life?

d) Is there any help that you need from me to get you to achieve your goals and graduate with excellence?

The answers given in this transparent, non-judgemental and safe space have helped me much and also improved my teaching techniques. It has also enabled me to help the student find coping mechanisms to deal with past and current stresses.

\subsubsection{Letter of Thanks for Group or Project Leadership}

Every group leader is given a letter of thanks on an official letterhead. This letter places on record my thanks and appreciation for his/her group leadership and undertaking this responsibility in a confident, empathetic, exemplary and intelligent manner. Additionally, the letter summarises the key points of the project concerned and the objectives achieved. This letter is also important in that it adds value to the student's curriculum vitae and enhances key graduate skills that will be needed in the world of work.

\subsection{The Power of Personal Time Management}

Research has shown that $80 \%-95 \%$ of college students procrastinate and about $50 \%$ procrastinate in a consistent and problematic manner resulting in detrimental academic performance e.g. poor grades and course withdrawal and increased health risks such as depression and anxiety. [17], 
[18] One theoretical framework that bears direct relevance to time management is self-regulated learning. [19] This involves an individual's behavioural attempts to plan, monitor and regulate time use such as creating study schedules and allocating time for various activities. Empirical evidence suggests that that these types of effective time management tools are associated with greater academic achievement [20,21,23].

Therefore, personal time management strategies and understanding the importance of prioritization helps student to avoid "the common trap of thinking they have unlimited "free" time when they are not attending class." [24] It is therefore beneficial to the educator and the student to engage in a proactive and focused discussion on implementing time management strategies and in doing so, creates a sense of independence and ordered organisation of time and priorities for the student. To this end, I developed a template entitled "Managing my Life Timetable" (See Appendix B). The student needing assistance in time management skills and strategies, schedules an appointment with me. We discuss the current situation and often the student is astounded at the amount of time wasted doing nothing progressive or constructive. This is a major light-bulb moment for the student as they are requested to calculate the seconds wasted. So if 3 days in total are currently wasted in a week, calculate: 3 days $\mathrm{x}$ 24 hours $\times 60$ minutes $\times 60$ seconds $=$ ? Thereafter, after much astonishment at this waste of precious time, we together look at what makes a typical day and how best to use the time of 24 hours per day while incorporating all aspects of life. In order to be accountable, the student then through any form of social media, sends me a brief weekly update of accomplishments, challenges and potential solutions. On mutual agreement, these updates cease when the student has taken full ownership of this aspect of his/her life.

\subsection{The Power of Reflective Practice}

Reflection is an important higher education strategy as students can benefit by respectively, challenging old and exploring new personal and professional perspectives [25] and broadening their knowledge about themselves, their strengths and their challenges and using these to become more solution oriented and success driven. Reflective practice can take many forms inclusive of but not limited to blogging, [25] peer-videoing, [26] diaries, [27] and electronic reflective practice. [28] The skills of selfawareness, critical analysis, synthesis and evaluation [29] are developed by the student as they undertake any form of reflective practice. These developmental skills also add value to the graduate attributes that universities strive to achieve.

I have started using this mode of motivation in my Honours class $\left(4^{\text {th }}\right.$ years) which largely uses flipped classroom teaching techniques and who comprise mainly employed, older individuals. A one page questionnaire is given to each student at the conclusion of each block lecture. The questions include: a) what did you learn during your planning process? b) how did you overcome any challenges encountered during the planning stage? c) what have you learnt from undertaking this project - for personal empowerment and for professional knowledge?

\section{Conclusion}

Given the South African context and the social and cultural backgrounds that my students come from, it is very inspiring to see how these techniques have empowered them to become mentally and emotionally confident. This confidence then shows itself in multiple ways inclusive of: a) decreased or minimal absenteeism, b) a major boost in assessment evaluations with all students endeavouring to achieve $75 \%$ and above for each assessment, c) a sense of accomplishment for the student, d) an increase in general well-being and personal empowerment and e) an enhancing of best teaching and learning practices. I am hopeful that these extrinsic motivation techniques do add value to the student, then to the graduate and in the long term, the professional who if s/he on advancing to management level, seeks to implement similar or even more empowering strategies to motivate the workforce, will thus economically and socially, further empower South Africa.

Motivation is probably the key factor that educators can focus on in order to empower learners and improve learning even though it is highly abstract and its measurement, challenging. [30] Intrinsic motivation is the preferred type as it is associated with meaningful learning, enhanced performance and positive well-being for the student in comparison to extrinsic motivation which must be provided by external resources such as the educator. [31] However, both types of motivation have been shown to positively influence study strategy, academic performance, adjustment and well-being in students in domains of education. Druger, in his article on Tips for Motivating Students concludes with this powerful statement: "As teachers, we try our best to motivate students and teach them to want to learn. As one colleague commented, "Our job as teachers is to inform and motivate students; but, if we motivate them, they inform themselves." So, keep doing what you do, and don't get discouraged.” [32]

\section{Statement of Competing Interests}

The author has no competing interests.

\section{References}

[1] Regan, J.A, "Motivating students towards self-directed learning," Nurse Education Today, 23, 593-599, 2003.

[2] Dearnley, C, and Matthew, B, "Factors that contribute to undergraduate student success," Teaching in Higher Education, 12(3), 377-391. 2007.

[3] Freitas, F.A, and Leonard, L.J, "Maslow's hierarchy of needs and student academic success," Teaching and Learning in Nursing, 6, 9-1, 2011.

[4] Maxwell, J.C, Sometimes you win, sometimes you learn, Center Street Hachette Book Group USA, New York, 2013, 101.

[5] D'Aloisio, A, "Motivating students through awareness of the natural correlation between college learning and corporate work settings," College Teaching, 54(2), 225-229, 2006.

[6] Bengtsson, M, and Ohlsson, B, "The nursing and medical students motivation to attain knowledge," Nurse Education Today, 30, 150156, 2010.

[7] Kuznetsov, A, and Kuznetsova, O, "Looking for Ways to Increase Student Motivation: Internationalisation and Value Innovation," Higher Education Quarterly, 65(4), 353-367, 2011. 
[8] Falout, J., Elwood, E, and Hood, M, "Demotivation: Affective states and learning outcomes,” System, 37, 403-417, 2009.

[9] Wentzel, K.R., Battle, A., Russell, S.L, and Looney, L.B, "Social supports from teachers and peers as predictors of academic and social motivation,” Contemporary Educational Psychology, 35, 193-202. 2010.

[10] Bahous, R., Bacha, N. N., Nabhani, M, "Motivating Students in the EFL Classroom: A Case Study of Perspectives," English Language Teaching, 4(3), 33-43, 2011.

[11] Hootstein, E. W, "The RISE model: Motivating at-risk students to learn,” The Clearing House, 70(2), 97-100. 1996.

[12] Stenmayr, R., Dinger, F.C, and Spinath, B, "Motivation as a Mediator of Social Disparities in Academic Achievement," European Journal of Personality, 26, 335-349, 2012.

[13] Aarnio, M., Nieminen, J., Pyorala, E and Lindblom-Ylanne, S, "Motivating medical students to learn teamwork skills," Medical Teacher, 32, e199-e204, 2010.

[14] ASSE Training \& Communications Branch leadership, "Motivating Learners With Enthusiasm \& Passion," ProfessionalSafety, 31, March 2012.

[15] Kittrell, D.L and Moore, G.E, "Student Motivation," NACTA Journal, 94-95. March 2013.

[16] Hanich, L.B, "Motivating students who struggle with Mathematics: An Application of Psychological Principles," Perspectives on Language and Literacy, 37(2), 41-45, Spring 2011.

[17] Tan, C.X., Ang, R.P., Klassen, R.M., Yeo, L.S., Wong, I.Y.F., Huan, V.S, and Chong, W.H, "Correlates of Academic Procrastination and Students’ Grade Goals,” Curr Psychol, 27, 135-144, 2008.

[18] Collier, P.J and Morgan, D.L, ““'Is that paper really due today?’” differences in first-generation and traditional college students' understandings of faculty expectations,” High Educ, 55, 425-446, 2008.

[19] Xu, J., Du, J, and Fan, X, "Finding our time”: Predicting students' time management in online collaborative groupwork," Computers \& Education, 69, 139-147, 2013.

[20] Klein, C.H, “Time Management Time Cards,” NACTA Journal, 105, December 2011.
[21] MacCann, C., Fogarty, G.J and Roberts, R.D, "Strategies for success in education: Time management is more important for part-time than full-time community college students,” Learning and Individual Differences, 22, 618-623, 2012.

[22] Zampetakisa, L.A., Bourantab, N, and Moustakisa, V.S, "On the relationship between individual creativity and time management," Thinking Skills and Creativity, 5, 23-32, 2010.

[23] Mirzaei, T., Oskouie, F, and Rafii, F, “Nursing students' time management, reducing stress and gaining satisfaction: a grounded theory,” Nursing and Health Sciences, 14, 46-51, 2012.

[24] Miquela, R, “Teching Latino students Time Management Skills,” The Hispanic Outlook in Higher Education, 21(12), 48, March 21 2011.

[25] Osman, G and Koh, J.H.L, "Understanding management students' reflective practice through blogging," Internet and Higher Education, 16, 23-31, 2013.

[26] Harford, J and MacRuairc, G "Engaging student teachers in meaningful reflective practice,” Teaching and Teacher Education, 24, 1884-1892, 2008.

[27] Billington T, "Promoting self-awareness through reflective practice," British Journal of Nursing, 22(1), 45, 2013.

[28] Mori, B., Batty, H.P, and Brooks, D, "The feasibility of an electronic reflective practice exercise among physiotherapy students,” Medical Teacher, 30, e232-e238. 2008.

[29] Schutz, S, "Reflection and reflective practice," Community Practitioner, 80(9), 26-29, Sep 2007.

[30] Hardre', P.L, “The Motivating Opportunities Model for Performance SUCCESS: Design, Development, and Instructional Implications,” Performance Improvement Quarterly, 22(1), 5-26, 2009.

[31] Kusurkar, R.A., Croiset, G, and Cate, T.H.T, “Twelve tips to stimulate intrinsic motivation in students through autonomysupportive classroom teaching derived from Self-Determination Theory,” Medical Teacher, 33, 978-982. 2011.

[32] Druger, M, “Tips for Motivating Students,” Journal of Natural Resources \& Life Sciences Education, 39, 92-93, 2010.

\section{APPENDIX A}

\section{A+ Certificate (not shown to scale)}

\section{Has being awarded this symbol as an indication of the final mark being the same in the final exam results}

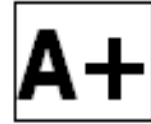

\section{Date handed out:}

\section{APPENDIX B}

\section{Managing my Life Timetable (not shown to scale)}




\begin{tabular}{|c|c|c|c|c|c|c|c|}
\hline TIME & Monday & Tuesday & Wednesday & Thursday & Friday & Saturday & Sunday \\
\hline $\begin{array}{c}06 \mathrm{~h} 00- \\
08 \mathrm{~h} 00\end{array}$ & & & & & & & \\
\hline $\begin{array}{c}8 \mathrm{hh00-}- \\
10 \mathrm{~h} 00\end{array}$ & & & & & & & \\
\hline $\begin{array}{c}10 \mathrm{~h} 00- \\
12 \mathrm{~h} 00\end{array}$ & & & & & & & \\
\hline $\begin{array}{c}12 \mathrm{~h} 00- \\
14 \mathrm{~h} 00\end{array}$ & & & & & & & \\
\hline $\begin{array}{c}14 \mathrm{ho0}- \\
16 \mathrm{ho0}\end{array}$ & & & & & & & \\
\hline $\begin{array}{c}16 \mathrm{~h} 00- \\
18 \mathrm{~h} 00\end{array}$ & & & & & & & \\
\hline $\begin{array}{c}18 \mathrm{~h} 00- \\
20 \mathrm{ho0}\end{array}$ & & & & & & & \\
\hline $\begin{array}{c}20 \mathrm{~h} 00- \\
22 \mathrm{~h} 00\end{array}$ & & & & & & & \\
\hline $\begin{array}{c}22 \mathrm{~h} 00- \\
24 \mathrm{ho0}\end{array}$ & & & & & & & \\
\hline $\begin{array}{c}24 \mathrm{~h} 00- \\
02 \mathrm{~h} 00\end{array}$ & & & & & & & \\
\hline $\begin{array}{c}\text { 02h00- } \\
\text { 04h00 }\end{array}$ & & & & & & & \\
\hline $\begin{array}{c}\text { 04h00- } \\
\text { 06h00 }\end{array}$ & & & & & & & \\
\hline
\end{tabular}

